The book is nicely produced, easy to read and well illustrated. It will certainly be of interest to the wide range of doctors and nurses who have dealings with these unfortunate patients and there must be few of us who do not!

\section{A Woman's Health}

By Gillian Strube. Pp. 164. Croom Helm, London, 1980. $£ 11.50$ (hardback), $£ 5.50$ (paperback).

This well written and perceptive book examines the foundations of health in the woman, her personality, upbringing, environment and attitudes of her family being included in the overall assessment. The reader is taken through chapters on menstruation, love and sex, contraception, pregnancy and marriage and middle and old age; the way in which social and psychological attitudes influence the individual and underlie apparent physical complaint emphasized and the theme of 'mens sane in corpore sano' maintained throughout.

Because of the various factors lying behind the problems encountered, the composition of a primary care team is of paramount importance, comprising as it does the receptionist, doctor, community nurse, midwife, psychiatric nurse and health visitor and the author outlines how this group can usefully be enlarged. Rightly it is pointed out that the resources of the National Health Services in the United Kingdom have largely been directed towards diagnosis and treatment of illness and that prevention has run a very poor second and an underlying theme in this book is the way in which the latter could be corrected.

At whom is this book aimed? It does not set out to be a text book of midwifery and gynaecology, yet should be read by all medical students; it is not a nursing text book, but should be read by all nurses; it does not attempt to cover all aspects of a primary health care team, though they will benefit from its contents. In short, it should be read by all who care for women, and the reviewer wonders whether its readership could not be extended even further and it be included by school teachers for group discussion by both sexes in upper schools, even though help would be required with the overtly medical sections. The author is a woman principal in general practice and has a deep understanding of the female at all ages. She is to be congratulated on her achievement. 